\title{
Toxicity of Metal Implants and Their Interactions with Stem Cells: A Review
}

\author{
Azin Mirzajavadkhan, Saba Rafieian, Muhammad Hasibul Hasan
}

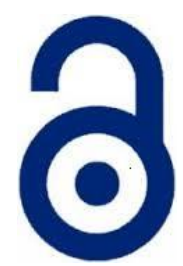

Received: 04 February 2020

Accepted: 18 March 2020

Published: 30 March 2020

Publisher: Deer Hill Publications

(c) 2020 The Author(s)

Creative Commons: CC BY 4.0

\begin{abstract}
The development of biomaterials has increased rapidly in order to alter the fate of stem cells and use them in therapeutic applications. Currently, many biomaterials are used in the biomedical industry. Biomaterials act as a "nitch" which is an environment regulating the development and self-renewal behaviour of stem cells. The stem cells receive signals from the "nitch" and proceeds accordingly. In order to control the behaviour of stem cells, the chemical and physical properties of the biomaterial should be taken into consideration. This review paper focuses on the different type of metals used in biomaterials, identifying their current issues and challenges including fatigue, corrosion resistance, and the toxicity caused by metal ions released in the body. It also provides detailed explanations about the impact of various metal implants such as stainless steel, cobalt-chromium, and titanium on stem cells and the toxicity caused by the interaction of biomaterials and various trace elements with the hostile body environment.
\end{abstract}

Keywords: Stem cells, Biomaterials, Toxicity, Implants

\section{INTRODUCTION}

Metal implants were first introduced to the medical industry in the 16th century [1,2]. With the development of metals as biomaterials, the implant surgery advanced rapidly over the next few years [3]. Efforts continued to make implants with various combinations of metals but not all alloys can be implanted in the body due to corrosive reactions between the implant and the hostile body environment. Thus, it is crucial to implant metals that are biocompatible, causing no harm to the host, to prevent corrosion [4-7]. A metal's corrosion-resistance property determines the success of an implant; however, it is crucial to consider that the body has different $\mathrm{pH}$ values in each part so the metal implant can be corrosion resistant in one region but highly corrosive in another region [8]. In order for an implant to mimic the function of a bone in the body, it must have suitable mechanical properties and strong performances. These properties include Young's modulus, toughness, and ultimate tensile strength (UTS) which are summarized in the table 1 for the three main groups of stainless-steel, cobalt based, and titanium-based metallic implants [9]. As the table shows the high Young's modulus of the implant triggers the stress-shielding effect causing the bone to bear less force compared to the implant and undergo autophagy [8]. Biomaterials can change the fate of stem cells and use them in the therapeutic industry [10]. Due to the great proliferation and pluripotency ability of stem cells, they are increasingly being used in wound healing and tissues recovery function using stem cell transplantation. There are two types of stem cells: embryonic stem cells (ESC) and adult stem cells. Adult stem cells have limited applications due to their low rate of self-renewal but embryonic stem cells are an example of stem cells undergoing osteogenic differentiation obtaining from the inner cell mass of blastocyst-stage embryos [11,12-17]. Stem cells with high toxicity rate including metal-based nanoparticles and metal oxides nanoparticles (NPs) are demanding in medicine and industry. Their use includes cell tracking, drug targeting, coating the medical devices, sunscreens and fuel additive [15]. In order to use stem cells in regenerative medicine some aspects like proliferation, differentiation and self-renewal abilities should be considered [16]. Tissue engineers aim to control the rapid increase of stem cells without differentiation and segregate cells in locations with specific lineages.

\section{INTERACTION OF BONE WITH STEM CELLS}

Due to the great proliferation and pluripotency ability of stem cells, they are increasingly being used in wound healing and tissues recovery function by stem cell transplantation. Embryonic stem cells are an example of stem cells undergoing osteogenic differentiation obtaining from the inner cell mass of blastocyst-stage embryos $[12,13,14]$. Bone biomaterials provide support for stem cells by creating a platform for growth and adhesion. The surface properties

A. Mirzajavadkhan, S. Rafieian and M. H. Hassan $₫$

Department of Mechanical Engineering

Ryerson University, Canada

E-mail: hasibulhasan@ryerson.ca

Reference: Mirzajavadkhan, A., Rafieian, S. and Hassan, M. H. (2020). Toxicity of Metal Implants and Their Interactions with Stem Cells: A Review. International Journal of Engineering Materials and Manufacture, 5(1), 2-11. 
directly control the adhesion, proliferation, differentiation, and migration of stem cells while the mechanical properties of the surface which stem cells grow on changes their fate (Figure 1). Stem cells help the maturation of osteoblasts and secretion of matrix materials and calcification; which would lead to the formation of new bones. New bone formation involves various pathways containing osteogenic differentiation of cells that leads to bone repair [17]. According to recent research great mechanical strength, degradation behaviour, and osteogenic properties are characteristics of biomaterial stem cells [14].

\section{STEM CELL PROLIFERATION IN TISSUE ENGINEERING}

Cells, including stem cells, can sense multiple extracellular signals from their microenvironment and simultaneously convert them into coherent environmental signals to regulate cell behaviour. Nonspecific adhesion generally occurs through van der Waals, ionic, and electrostatic forces [18]. The cell adhesion process consists of a series of cascaded reactions, including the following four steps [19]:

1. Cell adhesion

2. Cell spreading (proliferation)

3. Cytoskeletal organization

4. Formation of focal adhesions

lonic bonding or van der Waals forces are the initial adhesion parameters while this interaction is fast and temporary it promotes a focal adhesion plaque. A series of biological steps shown in figure 2 lead to enabling the signal adaptor proteins with the focal adhesion [20]. In tissue engineering stem cells and nanomaterials have a wide variety of applications such as nanomaterial scaffolds with the ability to resemble the fibrous nanostructure of a natural extracellular matrix (ECM). Engaging fresh cells at the bone failure site combined with grafting scaffolds assures bone healing. These nanocomponent scaffolds support the mesenchymal stem cells (MSCs) -multipotent cells that can distinguish into a variety of cell types- by helping in adhesion, distribution, proliferation, and differentiation (figure 3). They also allow migration and delivery of nutrients to the cell [21].

Based on a research that focused on the impacts of surface roughness $(1-150 \mathrm{~nm})$ on embryonic stem cells. The research concluded that undifferentiated stem attached rapidly to the smooth surface $(R=1 \mathrm{~nm})$ and the adherence decreased as the surface roughness increased. The rough surfaces caused sudden differentiation while, the smooth surface maintained its production and self- reproduction abilities [22]. Nanotopography can simply control the stem cell fate and its self-renewal properties on its own in the absence of differentiating induced agents [15].

Table 1: Mechanical properties of metal implants and bone [9]

\begin{tabular}{lccc}
\hline \multicolumn{1}{c}{ Materials } & Young's modulus(GPa) & Ultimate tensile strength(MPa) & Fracture toughness $(\mathrm{MPa} \sqrt{\boldsymbol{m}})$ \\
\hline CoCrMo alloys & 240 & $900-1540$ & $\sim 100$ \\
316L stainless steel & 200 & $540-1000$ & $\sim 100$ \\
Ti alloys & $105-125$ & 900 & $\sim 80$ \\
Mg alloys & $40-45$ & $100-250$ & $15-40$ \\
NiTi alloys & $30-50$ & 1355 & $30-60$ \\
Cortical bone & $10-30$ & $130-150$ & $2-12$ \\
\hline
\end{tabular}

a)

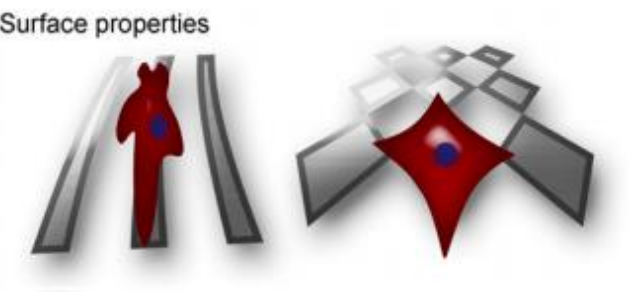

b) Mechanical properties
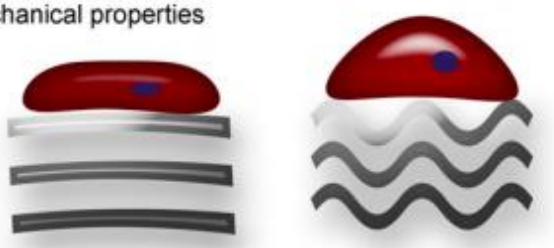

Figure 1: a) surface properties b) mechanical properties of stem cells [10].

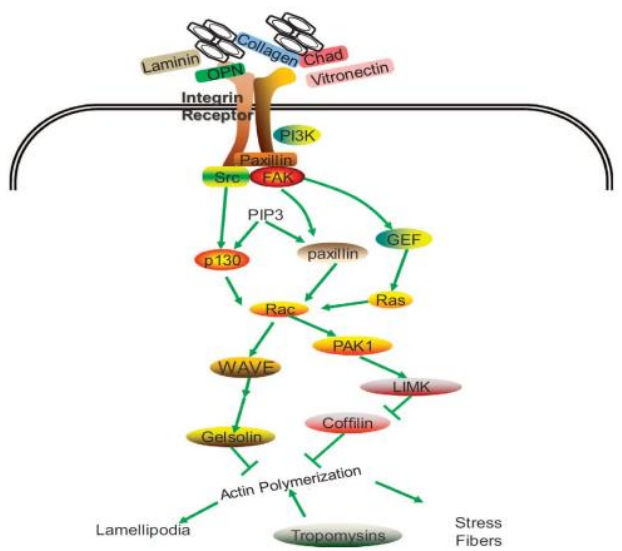

Figure 2: The signalling pathway in the adhesion of stem cells to bone biomaterials [17]. 


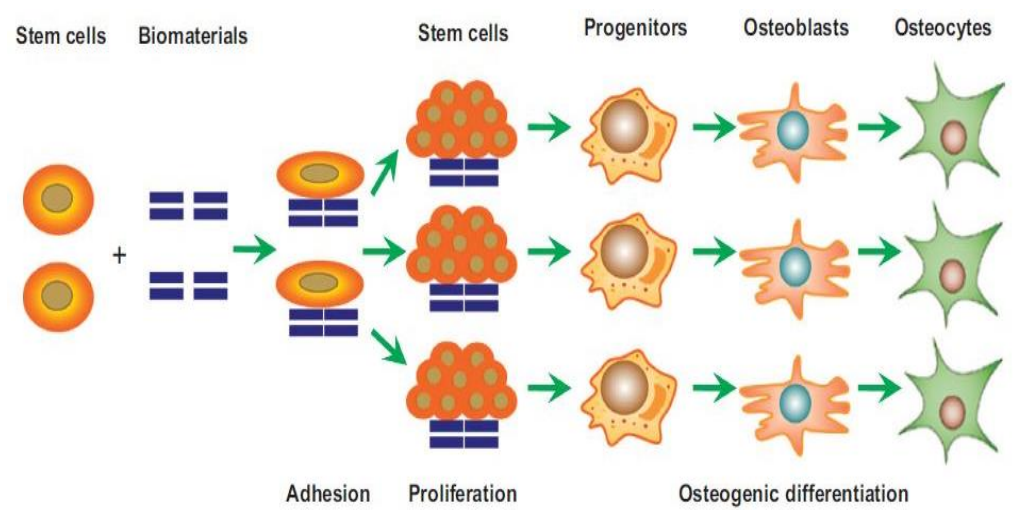

Figure 3: Adhesion, proliferation, and differentiation of bone biomaterials in contact with stem cells [17]

Table 2: Types of neurotoxicity and their impact on individuals [36]

\begin{tabular}{ll}
\hline Types of Neurotoxicity & \multicolumn{1}{c}{ Impact } \\
\hline Peripheral neuropathy & Paraesthesia, weakness, and anaesthesia with blood cobalt concentration of more than \\
250 $\mu \mathrm{g} / \mathrm{L}$.
\end{tabular}

The greatest concern in using biomedical applications such as scaffolds is biocompatibility and cytotoxicity which can jeopardize the overall health of the patients who are using biomedical implants. In this case in vitro and in vivo assessment of nanoscale materials before the clinical trial should be accomplished. An understanding of the interaction of stem cell with nanomaterial scaffold at the cellular and molecular level could facilitate the rational design of new substrates toward successful stem cell-based therapies. Scaffolds possess a variety of characteristics that could activate cellular reactions. These characteristics are consist of the following:

- Size of nanomaterials that scaffolds are made of can alter the behaviour of stem cells including their proliferation.

- Surface characteristics such as the roughness effects the interactions of stem cells. Nanomaterials on the surface of the scaffolds cause roughness which increases the chance of absorbing proteins and easing the differentiation of stem cells [23].

- Alignment of nanomaterials that defines the effect of the orientation of nanomaterials inside the substance. It is demonstrated that aligned nanofibers are more potential than randomly oriented substrates to grow collagen fibres on it [24].

- Chemistry of the surface and nanomaterials used on their surface should also be considered as a key characteristic affecting proliferation and differentiation of stem cells [25].

\section{NEUROTOXICITY, STEM CELLS, AND METALS}

Stem cells in the brain are involved in many brain functions such as memory, learning, mood, and olfaction [26]. The process of neurogenesis and neuronal development in adults is completed in an environment in the central nervous system (CNS). Neural stem cells are a type of somatic cells that have the ability to regenerate itself for long periods of time and generate various distinct neural lineages. CNS produces neural stem cells in the brain and can encounter extensive damage when exposed to heavy metals. This exposure causes cellular stress regulating autophagy [27]. In metal on metal prosthesis toxicity occurs after few years [28]. The stable part of the prosthesis is mainly made of titanium with a slight amount of vanadium, chromium, aluminium, cobalt, molybdenum or nickel; however, the bearing surface can be made of polyethylene, ceramic, stainless steel or cobalt/chromium combinations [29]. The metal-on-metal (MoM) or ceramic-on-metal (CoM) prosthesis is more durable compared to the polyethylene-onmetal (PoM) or polyethylene-on-ceramic prosthesis since the polyethylene cup causes wear in the prosthesis [30].

The MoM prosthesis contains chromium/cobalt bearings that can wear and lead to in vitro cytotoxicity [31-32]. The size, shape, and concentration of the wear particles contribute to the damage it causes [33]. In a case of wellfunctioning prosthesis, the concentration of cobalt chromium increases in the hole blood and serum in the first year of implantation of the prosthesis and decreases in the following years [34]. Metal ions in the prosthesis can also, contribute to its failure and can be a threat to local tissues [35]. 
Based on research done on patients neurotoxicity occurs in three ways in patients with prosthesis Peripheral neuropathy, Sensorineural Hearing-loss and Visual impairment which are all involved in cobalt intoxication [36]. Table 2 summarizes these points and provides examples of such case.

\subsection{Ferrous Metals}

\section{Stainless steel}

Stainless steel is an iron-based alloy that contains 11-30 wt\% of chromium and some percentage of nickel. There are four types of stainless steel alloys: Martensitic, Austenitic, Ferritic, and Duplex (Austenitic and Ferritic). However, only Austenitic stainless steel is used as implants due to its high corrosion resistance property [37]. Stainless-steel implants have suitable mechanical properties, easy production, and low cost [38]. Its corrosion resistance property is mainly due to the passivity layer built on top of stainless steel made of chromium oxide. Although the passivity layer is strong it does not make the alloy completely corrosion resistant especially in contact with body fluids [8]. Mainly pitting corrosion occurs causing metal ions to be released in the body resulting in various allergies [38]; however, crevice, fatigue, and stress corrosion cracking have also been reported (Figure 4) [39]. Researchers believe that one of the best ways to enhance the metal implants is to introduce Nano structuring with various processing techniques. For instance, severe plastic deformation (SPD) is the process in which high considerable amount of strain is subjected to a bulk material to produce an ultra-grained metal [41-43].

Nanostructure stainless steels have unique mechanical properties due to their small grain size and high-volume boundaries. Research indicates that nano-structuring stainless steel results in uniform grain size and distribution [44]. Nanostructured stainless steel increases the thickness and density of the passivity layer resulting in better biocompatibility and reducing corrosion [38]. Observations revealed that size, depth, and the number of pitting corrosions decreased in the nanostructured stainless steel compared to the conventional stainless steel implant [44].

\section{Iron}

Iron oxide nanoparticles are used in MRI as a tracking agent for stem cells. The nature of these nanoparticles is to accumulate in a specific region which leads to localized concentrations and causing toxicity with high cytotoxic levels $(100 \mathrm{mg} / \mathrm{ml})$. Cytotoxicity depends on the oxidation state of iron, coating and, interactions between particles and proteins. Iron (Fe) ions are a cofactor for metalloproteins (e.g. Heme) and are usually used in oxidation-reduction reaction [45,46]. One of the potential materials for temporary implants in the body is iron-based alloys. Fe is predominantly bound in insoluble degradation products whereas a considerable amount of Manganese (Mn) exists in the solution. $\mathrm{Mn}$ is a particle which eliminates cytocompatibility of alloys involved in the implant. Biodegradable Fe-alloy is being used in different medical implants such as cardiovascular stents or osteosynthesis applications. Iron acts as a perfect material for degradable stents with no early restenosis caused by thrombosis, inflammation or local toxicity. Comparing to stainless steel $316 \mathrm{~L}$ and cobalt-chromium alloy, iron-based stents remain intact for a longer time inside the veins while a faster degradation rate was expected. Furthermore, by adjusting the Mn content in solution the degradation rate of iron-based stents would be adjusted as desired $[47,46]$.

In a research using mouse fibroblast 2 T3, L929, primary cells from the human umbilical vein endothelial cells, and mouse bone marrow stem cells the cytotoxicity of pure iron and iron-based alloys was investigated. By studying the eluates of TWIP (Fe - $21 \mathrm{Mn}-0.7 \mathrm{C}$ ) and TWIP-1pd (Fe-21 Mn - 0.7C -1Pd) on metabolic activity and viability of human umbilical vein endothelial cells (HUVECs), it can be obtained that an increase in eluate concentration causes a decrease in both viability and metabolic activity, while an increase in the eluate concentration causes a decrease in these trends. Simulated body fluid (SPF) is a factor that causes a slight decrease in this trend as well. Endothelial cell growth medium (ECGM) as a control factor can enhance the loss of viability and metabolic activity due to increase in volume which is shown in figure $5[45,48]$.

Adding Fe2+ slightly reduce the viability a metabolic activity and concentration more than $2 \mathrm{mmol} / \mathrm{l}$ causes a significant decrease. Adding Fe3+ and $\mathrm{Mn} 2+$ induce an immediate decline in the trend of viability and metabolic activity, while concentration of more than $0.5 \mathrm{mmol} / \mathrm{l}$ has a conflicting effect on cells. $\mathrm{Mn} 2+$ has the least tolerance with the steepest trend among obtained the results.

Iron is an element in the human body that is kept nontoxic and soluble while bound to transferrin exclusively. This important element that is used for biomedical devices through aerobic conditions known as "reactive oxygen intermediates" (ROIs) will convert the free Fe ions to harmful radicals such as hydroxyl radicals (HO) generated from superoxide $(\mathrm{O} 2-)$ and hydroxide peroxide ( $\mathrm{H} 2 \mathrm{O} 2)$. This reaction also can occur accidentally within incomplete mitochondrial reduction-oxidation or intentionally through activated phagocytic cells. During this reaction, electrons are transferred between $\mathrm{Fe} 2+$ and Fe3+. The acidic chloride salts dissolved with Fe lowers the $\mathrm{PH}$ values of the resulting solution as 3.2 for $\mathrm{FeCl} 2$ and 1.7 for $\mathrm{FeCl}$. This very low $\mathrm{PH}$ leads to immediate sedimentation of insoluble products. Neurodegeneration and oxidative stress are the results from an accumulation of iron due to dyshomeostasis while oxidative stress results in an increased rate of autophagy. Iron ions released from metal implants increase the concentration of iron in the blood causing toxicity which it usually damages the liver and heart causing coma, shock, liver failure, organ damage, and if not dealt with in some cases death. 


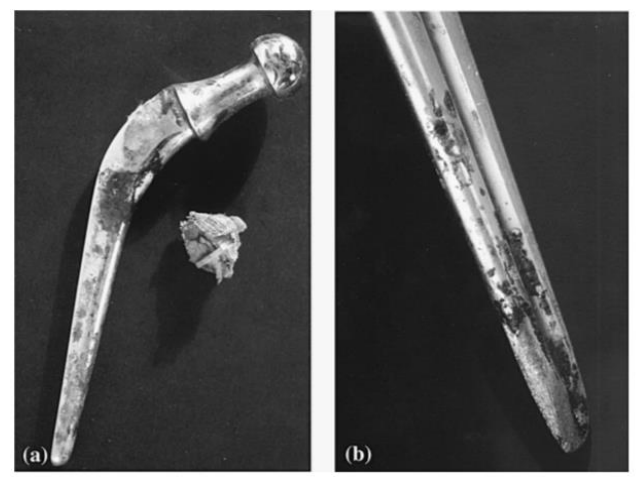

Figure 4: a) Corrosion scale on a Charnley stainless steel stem, and (b) pitting and corrosion of a Muller stainless steel stem after implant removal [40].

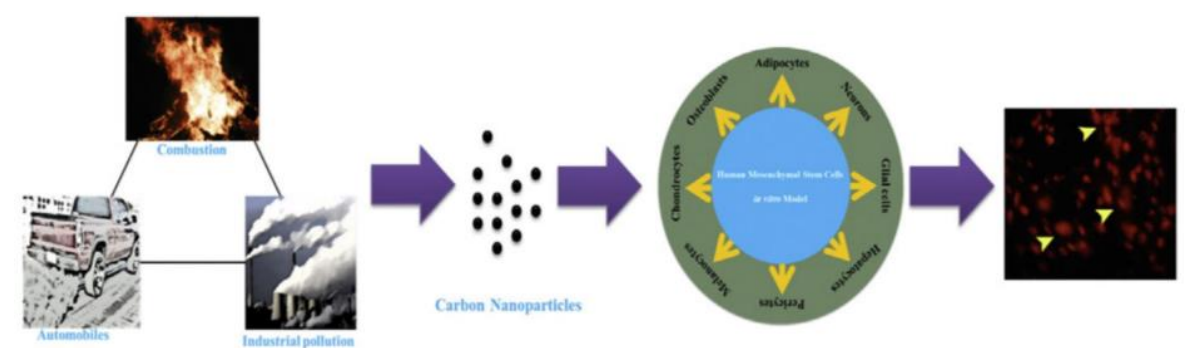

Figure 6: The sources of carbon nanoparticles and the cells that they affect [49]

\subsection{Non-Ferrous Metals}

\section{Carbon}

Carbon nanotubes and Nano diamonds are known as carbon-based nanomaterials with a variety of medical applications followed by the cellular toxicity on human Mesenchymal stem cells (MSCs) [49]. The studies are evaluating the toxic effects of engineered nanomaterials on health and environments and developing safe nanomaterials in commercial products [51]. Nanoparticles such as carbons released from combustion, automobiles and industrial pollution have an impact on human MSCs in vitro model effect on adipocytes, neurons, osteoblasts, chondrocytes, melanocytes, etc (figure 6). Carbon nanotubes are hollow tubes containing carbon having high strength, flexibility, electrical and thermal conductivity. They are used in scaffold due to surface characteristic and morphology resulting in effective cell attachment, differentiation, and proliferation [50].

Carbon nanotubes have a fibrous-like shape with the similar toxic properties to asbestosis causing lung inflammation and fibrosis [52]. Therefore, the health organizations have strict measures of time exposure while being operated. Carbon nanotubes are ensured about their biocompatibility in contact with MSCs and neural stem cell (NSC) during tissue healing. Analysing the cell cycle using flow cytometry shows the effect of carbon nanoparticles on cell cycle progression which is human MSCs were arrested by CNP causing morphological and functional changes [49].

The cytotoxicity of carbon nanoparticles is impacted by functionalization that alters the hydrophobicity of the surface and prevents direct contact between cells and carbon nanotubes [53]. Still, the long-term toxicity of scaffolds into human body need to be studied. Diamonds in Nano-size have near-infrared photoluminescence and magnetic properties. They have lower cytotoxicity compared to carbon nanotubes and are well-tolerance in different cell environments. Nano diamonds do not cause oxidative stress, however their low cytotoxicity they change the cell morphology [50].

\section{Titanium}

Titanium alloys are favoured by most surgeons and clinicians because of its low density compared to other biomaterials (60\% density of stainless steel and nearly 50\% density of cobalt) [8], high corrosion resistance due to strong passive layer of $\mathrm{TiO}_{2}$ which has the ability to reconstruct itself instantly even if the passivity layer is damaged and a better biocompatibility compared to other implants without mutagenicity [54-55]. Usually when implants are inserted in the body, the body generates a capsule marking the implant as a foreign object in the body and causing loosening of the prosthesis; however, titanium implants are the only systems that do not react with any surrounding tissue and completely binned with the bone without making any capsule [56] making them useful in the orthopaedic industry. Titanium implants are generally used in long-term devices such as hip replacements due to their bonebonding ability [8]. Although its advantages the challenge to develop a satisfactory titanium implant with high wear resistance and excellent bending strength still remains [8]. 


\section{Aluminium}

Aluminium in a biological environment has neurological malfunctions such as memory loss. Parkinson's disease and Alzheimer's disease are mainly due to aluminium accumulation in the brain [57]. Most aluminium toxicities cause neurological and non-neurological damages [58] such as brain damage, neurotoxicity, digestive disorders, contact dermatitis, breast cancer, anaemia, osteomalacia and encephalopathy [59]. Aluminium particles act similar to Fe metals while binding to transferrin in the blood and causing toxicity. They act as inhibitors in cell proliferation during progression and expression of regulating cells associated with cell cycle processes and apoptosis [60]. In a research, the cytotoxic effect of aluminium particles was evaluated using human MSCs in contact with $\mathrm{Al}_{2} \mathrm{O}_{3}$ nanoparticles for different times including 48 and 72 hours. The measurement of cell viability of human MSCs is a factor that shows the cytotoxicity of $\mathrm{Al}$ nanoparticles. Figure 7 compares the time and dose-dependent manner of $\mathrm{Al}_{2} \mathrm{O}_{3}$, concluding that in a low concentration of $\mathrm{Al}_{2} \mathrm{O}_{3}-\mathrm{NPs}$ slight reduction in cell viability is illustrated while in higher concentrations and time of $\mathrm{Al}_{2} \mathrm{O}_{3}-\mathrm{NPs}$, cell viability reaches up to $80 \%$ of cell death. Therefore, it can be concluded that aluminiumbased nanoparticles have a vital effect on human MSCs including viability and proliferation [61].

\section{Tantalum}

Tantalum-based implants have bone bonding ability, absorbing feature due to high workability and fracture stiffness [62]. The amount of toxicity and biocompatibility of a metal determines how the tissue responds to the implant [63]. An ideal implant has proper mechanical properties, high fatigue and corrosion resistance, proper density and a Young's modulus relatively close to the bone's Young's modulus to reduce stress accumulations in the prosthesis.

$\mathrm{Ta}$ is a hard material with the features of ductility, high chemical resistivity and proper apposition to bones [64]. The modulus of elasticity is $186 \mathrm{GPa}$ with a density of $16.6 \mathrm{~g} / \mathrm{cm}^{\wedge} 3$ which makes it a useful metal in orthopedic applications [65]. Tantalum metal can naturally form an oxide layer on the implanted tool in the body and facilitate bone growth. Ta is corrosion resistance due to the stable protective oxide layer of $\mathrm{Ta}_{2} \mathrm{O}_{5}$ on the surface. However, any defects in the oxide layer in the surface causes the release of carcinogenic $\mathrm{Ni2}+$ ions in the body [66]. Comparing to titanium, tantalum-based implants possess higher biocompatibility in bulk form and powder form. According to the research done on animal models, ignoring the position and form of an implant and the tissue type, tantalum demonstrate no inflammatory response. Porous tantalum-based implants have been recently developed for total implants in arthroplasty. Figure 8 shows a total shoulder implant made of porous tantalum-based material and the structure of the implant ease the possibility of osseointegration. However, the porous structure causes a significant decrease in elastic modulus and the weight of the implant [67].

\section{Zinc}

Zinc and zinc-based alloys possess biodegradable properties between the elements used in biomedical devices [69]. The by-product of zinc corrosion $\left(\mathrm{Zn}^{2+}\right)$ in physiological systems controls basic cellular processes. Despite the harmful effects of $\mathrm{Zn}^{2+}$ on smooth muscle cells causing restenosis in arteries, it causes stimulation on osteogenesis of bones. Zinc in a pure state has a low strength (UTS $\sim 30 \mathrm{MPa}$ ) with plasticity $(e<0.25 \%)$ that are not enough for most medical device applications. Developing high strength and ductility zinc with sufficient hardness, while retaining its biocompatibility, is one of the main goals of metallurgical engineering [70]. Although it's poor strength and plasticity zinc provides few benefits as a biomaterial. Zinc is a crucial trace element in biological systems and is a necessary metal for fundamental functions of the body such as cell growth and protein metabolism; therefore, degradation of the implant releasing $\mathrm{Zn}^{2+}$ will consolidate into the normal metabolic activity of the patient without having toxic side effects [71]. Zinc also possesses high chemical activity with an electrode potential of $-0.762 \mathrm{~V}$. Thus, performing a steadier rate of degradation in relation to the passive layer of corrosion formed on the surface of the implant [7073]. Comparing to other degradable metals, due to its low melting point, low chemical reactivity, and moderate machinability zinc is much easier to caste and process for biomedical implants. The melting point of zinc is such that it can perform easily in the air $[69,70]$.

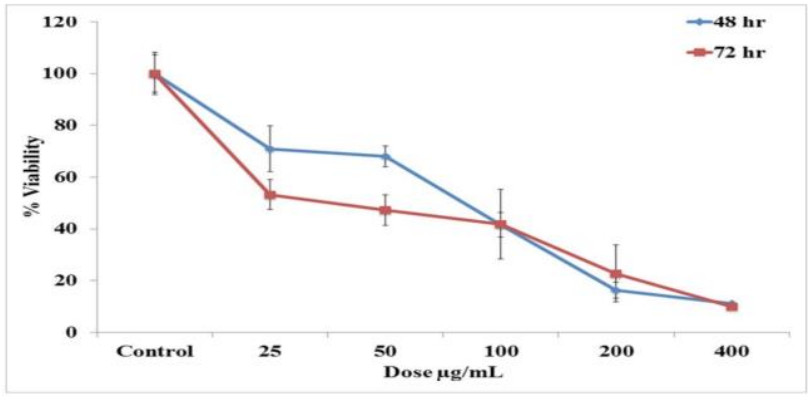

Figure 7: Treating human MSCs at various doses for 48 and $72 \mathrm{H}$ and studying the cell viability [61]

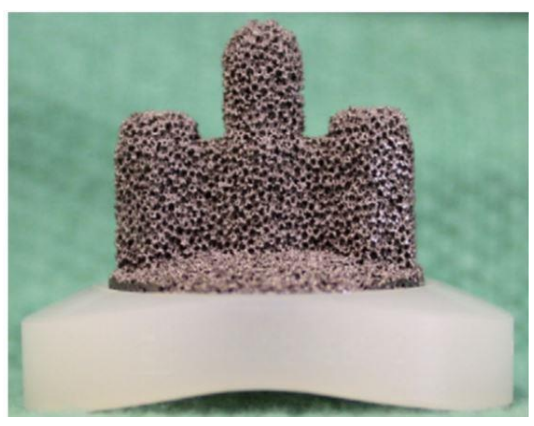

Figure 8: The total shoulder implant with the porous tantalum-based material [68] 
Table 3: Effects of the elements released from $\mathrm{Co}-\mathrm{Cr}$ prosthesis overtime

\begin{tabular}{cl}
\hline Element released & \multicolumn{1}{c}{ Impact } \\
\hline Cobalt & $\begin{array}{l}\text { Neurological effects (tinnitus, vision-loss, vertigo), endocrine, haematological, cardiological, } \\
\text { contact dermatitis, headaches, memory loss, fatigue, cramps. Hypersensitivity to cobalt } \\
\text { occurs more frequently in patients with pre-implant osteolysis showing a delayed } \\
\text { hypersensitivity reaction [1,75] }\end{array}$ \\
Chromium & $\begin{array}{l}\text { More genotoxic compared to cobalt [76]. Decreases fertility in male and female individuals } \\
\text { by reducing sperm production and ova quality [77] } \\
\text { Molybdenum } \\
\text { Low levels of molybdenum can cause irritation in eyes and skin. High amounts ingested can } \\
\text { cause diarrhea, infertility, damage in liver, kidney, and lungs [77] }\end{array}$ \\
\hline
\end{tabular}

\subsection{SuperAlloy/ Alloy \\ 1. $\mathrm{Co}-\mathrm{Cr}$}

$\mathrm{CoCr}$ - based implants are used in dentistry and artificial joints they were first used as implants in the 1930's. The strength of this alloys can be increased by cold-working. Due to $\mathrm{Cr}_{2} \mathrm{O}_{3}$ passivity layer, it is highly corrosion resistance compared to stainless steel [71]. It is used in applications that require long exposure to hostile body environment without fracture due to high fatigue resistance and high tensile strength [74]. There are serious concerns about elements such as cobalt, chromium, and molybdenum released from the prosthesis over time which directly impacts the DNA causing damage, toxicity, and inflammation. The following table summarizes the effects of ions released from a $\mathrm{CoCr}$ prosthesis in the body over time.

\section{CONCLUSIONS}

1. Development of stem cells and metal implants has enhanced the field of tissue engineering by studying the neurotoxicity and the side effects of various nanoparticles and trace elements released from implants in the body. It is important to consider that not all alloys can be implanted due to the corrosive reactions between the implant and the hostile body environment. PH values differ in each part of the body causing an implant to be more corrosive in one region compared to another. Thus, it is crucial to analyse the environment and characteristics of that region in the body and choose a compatible alloy.

2. Stem cells and nanomaterials have a wide variety of applications such as nanomaterial scaffolds which accumulate fresh cells at a bone failure site and combines grafting scaffold to increase bone healing. The main concern is biocompatibility and cytotoxicity of the scaffolds and the body which might jeopardize the health of an individual. In order to design new substrates for stem cell-based therapies, the interaction of nanomaterial scaffold and stem cells should be studied on a molecular and cellular level.

3. Interactive interaction of bone and stem cells shows the effectiveness of stem cells in the maturation of osteoblasts that leads to the formation of new bones. In tissue engineering, this behaviour is enhance using scaffolds to support mesenchymal stem cells. Various characteristics of scaffolds such as surface roughness, size, and alignment of nanomaterials that the scaffolds are made of controls the interaction of stem cells and bone.

5. Physical and chemical properties, application, biocompatibility with stem cells and more importantly the side effects and toxicity of biomaterials are the characteristics considered to choosing a suitable prosthesis. In the case of pitting corrosion of austenitic stainless steel which is an iron-based alloy, the release of metal ions cause various allergies and toxicities in the body. Iron released in the blood leads to serious liver and heart damage that could potentially cause death. Non-ferrous metal implants such as Carbon could be used for tissue healing. This metal is biocompatible in contact with MSC and NSC; however, the long-term toxicity of carbon in contact with stem cells should be studied further. Aluminium nanoparticles could cause serious neurological malfunctions. For example, the accumulation of Aluminium in the brain leads to Parkinson's and Alzheimer's disease. Likewise, the existence of this non-ferrous metal increases the viability and proliferation of human mesenchymal stem cells. The absorbing feature of Tantalum and the non-inflammatory response of this nonferrous metal is impressive, though it can lead to the release of carcinogenic $\mathrm{Ni2}+$ ions to the body. Using Zinc in medical devices shows no side effects but has very low strength. Superalloys are the main biomaterials for prosthesis with high fatigue resistance and tensile strength. Peripheral neuropathy, Sensorineural Hearingloss, and Visual impairment are the different possible neurotoxicity that occur among patients with $\mathrm{CoCr}$ prosthesis which are all due to cobalt intoxication.

6. Titanium implants are considered long-lasting and most favoured due to its light weight and its ability to repeat loads. Titanium has a low Young's modulus compared to the conventional stainless steel, causing it to reduce the amount of stress on the bone. Unlike other metals that form a capsule around the newly placed implant claiming it as a foreign object, this implant is the only implant implants that directly bind to bone without forming a capsule around it and decrease the risk of corrosion and implant loosening. 


\section{REFERENCES}

1. Gotman I. Characteristics of metals used in implants. J. endourol. 1997; 11(6): 383-389.

2. Park J, Lakes RS. Biomaterials: an introduction: SSBM; 2007.

3. Zardiackas LD, Kraay MJ, Freese HL, editors. Titanium, niobium, zirconium, and tantalum for medical and surgical applications. Astm, 2006.

4. Arnould C, Denayer J, Planckaert M, Delhalle J, Mekhalif Z. Bilayers coating on titanium surface: The impact on the hydroxyapatite initiation. J. Colloid Interface Sci. 2010; 341(1): 75-82.

5. Arnould C, Volcke C, Lamarque C, Thiry PA, Delhalle J, Mekhalif Z. Titanium modified with layer-by-layer solgel tantalum oxide and an organodiphosphonic acid: A coating for hydroxyapatite growth. J. Colloid Interface Sci. 2009; 336(2): 497-503.

6. Geetha M, Singh AK, Asokamani R, Gogia AK. Ti based biomaterials, the ultimate choice for orthopaedic implants -A review. Prog. Mater Sci. 2009; 54(3): 397-425.

7. Heimann RB. Structure, properties, and biomedical performance of osteoconductive bioceramic coatings. Surf.Coat. Technol. 2013; 233: 27-38

8. Q. Chen and G. A. Thouas, "Metallic implant biomaterials," Materials Science \& Engineering R, 87, 1-57, 2015.

9. H.J.R.M. Long, Biomaterials 19 (1998) 1621-1639.

10. S. Martino et al, "Stem cell-biomaterial interactions for regenerative medicine," Biotechnology Advances, vol. 30, (1), pp. 338-351, 2012.

11. P. Kerativitayanan, J. K. Carrow and A. K. Gaharwar, "Nanomaterials for Engineering Stem Cell Responses," Advanced Healthcare Materials, vol. 4, (11), pp. 1600-1627, 2015

12. Ma MS, Kannan V, de Vries AE et al. Characterization and comparison of osteoblasts derived from mouse embryonic stem cells and induced pluripotent stem cells. J Bone Miner Metab 2017; 35: 21-30

13. Kang Y, Georgiou Al, MacFarlane RJ et al. Fibronectin stimulates the osteogenic differentiation of murine embryonic stem cells. J Tissue Eng Regen Med 2015; 11: 1929-1940.

14. Yu Y, Al-Mansoori L, Opas M. Optimized osteogenic differentiation protocol from R1 mouse embryonic stem cells in vitro. Differentiation 2015; 89:1 -10.

15. Tourinho PS, van Gestel CA, Lofts S, Svendsen C, Soares AM, Loureiro S. Metal-based nanoparticles in soil: fate, behavior, and effects on soil invertebrates. Environ Toxicol Chem. 2012; 31(8):1679-1692. [PubMed: 22573562]

16. R. Ravichandran, S. Liao, C. C. Ng, C. K. Chan, M. Raghunath, S. Ramakrishna, World J. Stem Cells $2009,1,55$.

17. Chengde Gao et al, "Bone biomaterials and interactions with stem cells," 5, (4), 253-285, 2017.

18. Jensen J, Kraft DCE, Lysdahl $\mathrm{H}$ et al. Functionalization of polycaprolactone scaffolds with hyaluronic acid and $\beta$-TCP facilitates migration and osteogenic differentiation of human dental pulp stem cells in vitro. Tissue Eng Part A 2014; 21: 729-739.

19. Zhukova Y, Hiepen C, Knaus $\mathrm{P}$ et al. The role of titanium surface nanostructuring on preosteoblast morphology, adhesion, and migration. Adv Healthcare Mater 2017, 1601244.

20. Aiyelabegan HT, Sadroddiny E. Fundamentals of protein and cell interactions in biomaterials. Biomed Pharmacother 2017; 88: 956-970.

21. Martins A, Pinho ED, Correlo VM, Faria S, Marques AP, Reis RL, et al. Biodegradable nanofibers-reinforced microfibrous composite scaffolds for bone tissue engineering. Tissue Eng Part A 2010; 16:3599-609.

22. W. Chen, L. G. Villa-Diaz, Y. Sun, Shinuo Weng, J. K. Kim, R. H. W. Lam, L. Han, R. Fan, P. H. Krebsbach, J. Fu, ACS Nano 2012, 6, 4094.

23. Lei B, Chen X, Wang Y, Zhao N, Du C, Fang L. Surface nanoscale patterning of bioactive glass to support cellular growth and differentiation. J Biomed Mater Res A 2010; 94:1091-9.

24. WangG, ZhengL,ZhaoH, MiaoJ, SunC, LiuH, etal.Construction of a fluorescent nanostructured chitosanhydroxyapatite scaffold by nanocrystallon induced biomimetic mineralization and its cell biocompatibility. ACS Appl Mater Interfaces 2011a;3: 1692-701.

25. Chen H, Fan X, Xia J, Chen P, Zhou X, Huang J, et al. Electrospun chitosan-graft-poly (varepsiloncaprolactone)/poly (varepsilon-caprolactone) nanofibrous scaffolds for retinal tissue engineering. Int J Nanomedicine 2011; 6:453-61.

26. Zhao C, Deng W, Gage FH: Mechanisms and functional implications of adult neurogenesis. Cell 2008, 132:645660.

27. Chatterjee S, Sarkar S, Bhattacharya S (2014) Toxic metals and autophagy. Chem Res Toxicol 27:1887-1900

28. S. M. Bradberry, J. M. Wilkinson and R. E. Ferner, "Systemic toxicity related to metal hip prostheses," Clinical Toxicology, vol. 52, (8), pp. 837-847, 2014.

29. Labek G, Thaler M, Janda W, Agreiter M, Stöckl B. Revision rates after total joint replacement: cumulative results from worldwide joint register datasets. J Bone Joint Surg Br 2011; 93-B: 293-297.

30. Rising JP, Reynolds IS, Sedrakyan A. Delays and difficulties in assessing metal-on-metal hip implants. N Engl J Med 2012; 367

31. Madathil BK, Lin Q, Hew C-L, Mohanty M. Hypoxia-like effect of cobalt chromium alloy micro particles on fibroblasts in vitro. J Orthop Res 2010; 28:1360-1367. 
32. V. Sansone, D. Pagani and M. Melato, "The effects on bone cells of metal ions released from orthopaedic implants. A review," Clinical Cases in Mineral and Bone Metabolism: The Official Journal of the Italian Society of Osteoporosis, Mineral Metabolism, and Skeletal Diseases, vol. 10, (1), pp. 34, 2013.

33. Polyzois I, Nikolopoulos D, Michos I, Patsouris E, Theocharis S. Local and systemic toxicity of nanoscale debris particles in total hip arthroplasty. J Appl Toxicol 2012; 32:255-269.

34. Jantzen C, Jorgensen HL, Duus BR, Sporring SL, Lauritzen JB. Chromium and cobalt ion concentrations in blood and serum following various types of metal-on-metal hip arthroplasties: a literature overview. Acta Orthop 2013; 84:229-236.

35. Andrews RE, Shah KM, Wilkinson JM, Gartland A. Effects of cobalt and chromium ions at clinically equivalent concentrations after metal-on-metal hip replacement on human osteoblasts and osteoclasts: Implications for skeletal health. Bone 2011; 49:717-723.

36. S. M. Bradberry, J. M. Wilkinson and R. E. Ferner, "Systemic toxicity related to metal hip prostheses," Clinical Toxicology, vol. 52, (8), 837-847, 2014.

37. Mettalic materials, J.R. Davies (Ed.), Handbook of Materials for Medical Devices, ASM International, Materials Park, Ohio, 2003, 21-50.

38. Brown RN, Sexton BE, Chu T-MG, Katona TR, Stewart KT, Kyung H-M, Liu SS. Comparison of stainless steel and titanium alloy orthodontic miniscrew implants: a mechanical and histologic analysis. 2014; 145(4): 496-504.

39. Hajizadeh K, Maleki Ghaleh H, Arabi A, Behnamian Y, Aghaie E, Farrokhi A, Hosseini MG, Fathi MH. Corrosion and biological behavior of nanostructured $316 \mathrm{~L}$ stainless steel processed by severe plastic deformation. Surf. Interface Anal. 2015; 47(10): 978-85.

40. J. Walczak, F. Shahgaldi, F. Heatley, Biomaterials 19 (1998) 229-237.

41. Azushima A, Kopp R, Korhonen A, Yang D, Micari F, Lahoti G, Groche P, Yanagimoto J, Tsuji N, Rosochowski A, Yanagida A. Severe plastic deformation (SPD) processes for metals. Cirp. Ann-Manuf. Techn. 2008; 57(2): 716-735.

42. Nie F, Zheng Y, Wei S, Hu C, Yang G. In vitro corrosion, cytotoxicity and hemocompatibility of bulk nanocrystalline pure iron. Biomed. Mater. 2010; 5(6): 065015.

43. Orlov D, Ralston K, Birbilis N, Estrin Y. Enhanced corrosion resistance of $\mathrm{Mg}$ alloy ZK60 after processing by integrated extrusion and equal channel angular pressing. Acta Mater. 2011; 59(15): 6176-6186.

44. P. M. Hashemi, E. Borhani and M. S. Nourbakhsh, "A review on nanostructured stainless steel implants for biomedical application," Nanomedicine Journal, vol. 3, (4), 202-216, 2016.

45. M. Schinhammer et al, "On the cytocompatibility of biodegradable Fe-based alloys,"Materials Science \& Engineering. C, Materials for Biological Applications, vol. 33, (2), 782-789, 2013.

46. Y. Yao et al, "Cobalt and nickel stabilize stem cell transcription factor OCT4 through modulating its sumoylation and ubiquitination," PloS One, vol. 9, (1), 86620, 2014.

47. Zhang ZN, Chung SK, Xu Z, Xu Y (2013) Oct4 maintains the pluripotency of human embryonic stem cells by inactivating $p 53$ through Sirt1-mediated deacetylation. Stem Cells.

48. Botquin V, Hess H, Fuhrmann G, Anastassiadis C, Gross MK, et al. (1998) New POU dimer configuration mediates antagonistic control of an osteopontin preimplantation enhancer by Oct-4 and Sox-2. Genes Dev 12: 2073-2090.

49. Periasamy, V. S., Athinarayanan, J., Alfawaz, M. A., \& Alshatwi, A. A. (2016). Carbon nanoparticle induced cytotoxicity in human mesenchymal stem cells through upregulation of TNF3, NFKBIA and BCL2L1 genes. Chemosphere, 144(Complete), 275-284. doi:10.1016/j.chemosphere. 2015.08.018

50. Wei F, Scholer HR, Atchison ML (2007) Sumoylation of Oct4 enhances its stability, DNA binding, and transactivation. J Biol Chem 282: 21551-21560.

51. Aitken, R.J., Hankin, S.M., Ross, B., Tran, C.L., Stone, V., Fernandes, T.F., Donaldson, K., et al., 2009. EMERGNANO: a Review of Completed and Near Completed Environment, Health and Safety Research on Nanomaterials and Nanotechnology Defra Project CB0409 Institute of Occupational Medicine Report. TM/09/01

52. Pacurari M, Castranova V, Vallyathan V. Single- and multi-wall carbon nanotubes versus asbestos: are the carbon nanotubes a new health risk to humans? J Toxicol Environ Health A. 2010; 73(5)

53. A. M. Schrand, J. Johnson, L. Dai, Saber M. Hussain, J. J. Schlager, L. Zhu, Y. Hong, E. O. Sawa, in Safety of Nanoparticles, Springer, New York 2009.

54. Schliephake H, Scharnweber D. Chemical and biological functionalization of titanium for dental implants. J. Mater. Chem. 2008; 18(21): 2404-24014.

55. T. Kodama, Kokubyo Gakkai zasshi, J. Stomatol. Soc. Jpn. 56 (1989) 263-288.

56. P.C. Ferreira, K.d.A. Piai, A.M. Magosso Takayanagui, S.I. Segura-Munoz, Rev. Lat. Am. Enfermagem 16 (2008) 151-157.

57. Savory J, Ghribi O. Can studies of aluminium toxicity in vivo and in vitro provide relevant information on the pathogenesis and aetiology of Alzheimer's disease? J Alzheimer's Dis 2007; 11:429-30; discussion 31-2.

58. S.V. Verstraeten, L. Aimo, P.I. Oteiza, Arch. Toxicol. 82 (2008) 789-802. 
59. Nam, S. M., Kim, J. W., Yoo, D. Y., Kim, W., Jung, H. Y., Choi, J. H., ... Yoon, Y. S. (2016). Effects of aluminum on the reduction of neural stem cells, proliferating cells, and differentiating neuroblasts in the dentate gyrus of D-galactose-treated mice via increasing oxidative stress. Journal of Veterinary Science, 17(2), 127-136.

60. Huang, D. M., Hsiao, J. K., Chen, Y. C., Chien, L. Y., Yao, M., Chen, Y. K., Yao, M., Chen, Y. K., Ko, B. S., Hsu, S. C., Tai, L. A., Cheng, H. Y., Wang, S. W., Yang, C. S., and Chen, Y. C. (2009) Biomaterials 30, 3645-3651.

61. V.S. Periasamy, J. Athinarayanan and A. A. Alshatwi, "aluminium oxide nanoparticles alter cell cycle progression through CCND1 and EGR1 gene expression in human mesenchymal stem cells," Biotechnology and Applied Biochemistry, vol. 63, (3), pp. 320-327, 2016.

62. Balla VK, Bodhak S, Bose S, Bandyopadhyay A. Porous tantalum structures for bone implants: Fabrication, mechanical and in vitro biological properties. Acta. Biomater. 2010; 6(8): 3349-3359.

63. Chaturvedi T. Allergy related to dental implant and its clinical significance. Clin Cosmet Investig Dent. 2013; 5: 57-61.

64. Helsen, J.A., Missirlis, Y.: Biomaterials - A tantalus experience. Springer, 2010

65. Tao, L., Wen, J., et al.: Enhanced osteo-integration on tantalum implanted polyetheretherketone surface with bone-like lastic modulus. Biomaterials 51 (2015), 173-183.

66. McNamara, K., Kolaj-Robin, O., et al.: Surface chemistry and cytotoxicity of reactively sputtered tantalum oxide films on NiTi plates. In: Thin Solid Films 589 (2015), p. 1-7.

67. Liu, Y., Bao, C., et al.: The physicochemical/biological properties of porous tantalum and the potential surface modification techniques to improve its clinical application in dental implantology. In: Materials Science and Engineering C 49 (2015), 323-329.

68. Bobyn, J.D., Toh, K.K., et al.: Tissue response to porous tantalum acetabular cups: A canine model. In: Journal of Arthroplasty 14 (1999) 347-354.

69. G. Katarivas Levy, J. Goldman and E. Aghion, "The Prospects of Zinc as a Structural Material for Biodegradable Implants-A Review Paper," Metals, vol. 7, (10), pp. 402, 2017.

70. G. Katarivas Levy, J. Goldman and E. Aghion, "The Prospects of Zinc as a Structural Material for Biodegradable Implants_A Review Paper," Metals, 7, (10), 402, 2017.

71. Liu, X.; Sun, J.; Qiu, K.; Yang, Y.; Pu, Z.; Li, L.; Zheng, Y. Effects of alloying elements (Ca and Sr) on microstructure, mechanical property and in vitro corrosion behavior of biodegradable $\mathrm{Zn}-1.5 \mathrm{Mg}$ alloy. J. Alloys Compd. 2016, 664, 444-452.

72. S. Pramanik, A.K. Agarwal, K.N. Rai, Trends Biomater. Artif. Organs 19 (2005) 15-26.

73. S. Shaham et al, "Fast Channel Estimation and Beam Tracking for Millimeter Wave Vehicular Communications," 2018.

74. Park J, Lakes RS. Biomaterials: an introduction: SSBM; 2007.

75. V. Sansone, D. Pagani and M. Melato, "The effects on bone cells of metal ions released from orthopaedic implants. A review," Clinical Cases in Mineral and Bone Metabolism: The Official Journal of the Italian Society of Osteoporosis, Mineral Metabolism, and Skeletal Diseases, vol. 10, (1), 34, 2013.

76. Papageorgiou I, Yin Z, Ladon D, et al. Genotoxic effects of particles of surgical cobalt chrome alloy on human cells of different age in vitro. Mutat Res 2007; 619:45-58.

77. K. Liber, L.E. Doig, S.L. White-Sobey, Ecotoxicol. Environ. Saf. 74 (2011) 1171-1179.

78. C. Delaunay, I. Petit, I.D. Learmonth, P. Oger, P.A. Vendittoli, Orthop. Traumatol. Surg. Res. 96 (2010) 894 904.

79. S. Shaham et al, "Privacy Preservation in Location-Based Services: A Novel Metric and Attack Model," 2018.

80. J.J. Ramsden, D.M. Allen, D.J. Stephenson, J.R. Alcock, G.N. Peggs, G. Fuller, G. Goch, CIRP Ann. Manuf. Technol. 56 (2007) 687-711. 